\title{
PENGARUH GAYA KEPEMIMPINAN, BUDAYA ORGANISASI \\ DAN KOMITMEN ORGANISASI TERHADAP KINERJA \\ PEGAWAI DINAS PERTANIAN KABUPATEN MAMUJU
}

\author{
Andi Ratna Sari Dewi \\ Dosen Fakultas Ekonomi dan Bisnis Unhas \\ Email :ratna fe@unhas.ac.id \\ Dr. Hasniaty \\ Dosen Fakultas Ekonomi Unversitas Fajar \\ Email :nitahasniaty@gmail.com
}

\begin{abstract}
Abstrak: Penelitian ini bertujuan dan menganalisis pengaruh budaya organisasi dan komitmen organisasi terhadap kinerja pegawai Dinas Pertanian Kabupaten Mamuju dan untuk mengetahui variabel yang paling dominan berpengaruh terhadap kinerja pegawai Dinas Pertanian Kabupaten Mamuju. Dalam penelitian ini yang menjadi populasi adalah seluruh pegawai Dinas Pertanian Kabupaten Mamuju pada tahun 2017 yaitu berjumlah 35 pegawai. Hasil penelitian menunjukkan bahwa variabel gaya kepemimpinan, budaya organisasi dan komitmen organisasi secara bersama-sama berpengaruh secara positif dan signifikan terhadap kinerja pegawai Dinas Pertanian Kabupaten Mamuju. Hasil analisis menunjukkan bahwa dari ketiga variabel yang diteliti, variabel komitmen organisasi mempunyai pengaruh paling dominan terhadap kinerja pegawai Dinas Pertanian Kabupaten Mamuju.
\end{abstract}

Kata kunci: Gaya Kepemimpinan, Budaya Organisasi, Komitmen Organisasi, Kinerja

\begin{abstract}
This study aims and analyzes the influence of organizational culture and organizational commitment to the performance of the employee of Agriculture Department of Mamuju Regency and to find out the most dominant variable affecting the performance of Mamuju Regency Agriculture Officer. In this study the population is all employees of the Department of Agriculture of Mamuju Regency in 2017 that amounted to 35 employees. The results show that the variables of leadership style, organizational culture and organizational commitment together influence positively and significantly to the performance of employees of the Mamuju District Agricultural Service. The result of analysis shows that of the three variables studied, the organizational commitment variable has the most dominant influence to the performance of the employee of the Agricultural Service of Mamuju Regency.
\end{abstract}

Keywords: Leadership style, organisational culture, organisational commitment, performance

\section{PENDAHULUAN}

Dalam menyelenggarakan kegiatan pemerintahan dan pembangunan, kedudukan dan peranan pegawai negeri sangatlah penting. Hal ini disebabkan karena pegawai negeri merupakan unsur aparatur negara yang melaksanakan pemerintahan dan pembangunan dalam mencapai tujuan nasional. Tangkilisan (2002, p. 25) menyatakan bahwa unsur manusia merupakan unsur penting, karena manusia selalu berperan aktif dan dominan dalam setiap 


\section{Jurnal Bisnis, Manajemen dan Informatika}

organisasi. Manusia adalah perencana, pelaku sekaligus penentu terwujudnya tujuan organisasi. Dengan demikian pegawai negeri dituntut untuk memiliki kemampuan dalam menjalankan tugas dan tanggungjawabnya untuk berpartisipasi dalam kegiatan pemerintahan, pembangunan dan kemasyarakatan secara efektif dan efisien.

Menyadari pentingnya peranan pegawai negeri tersebut pemerintah telah banyak melakukan kegiatan untuk memberdayakan pegawai negeri sehingga memiliki kemampuan dan kinerja yang optimal dalam upaya pencapaian tujuan nasional. Hal ini juga dijelaskan dalam Undang - Undang Nomor 43 tahun 1999 tentang pokok - pokok kepegawaian yang dalam penjelasannya menyatakan bahwa kelancaran penyelengaraan tugas pemerintahan dan pembangunan nasional sangat tergantung pada kesempurnaan aparatur negara khususnya pegawai negeri.

Dinas Pertanian Kabupaten Mamuju merupakan salah satu lembaga pemerintah yang mempunyai tugas dan fungsi pokok untuk melaksanakan kewenangan desentralisasi di bidang pertanian di Kabupaten Mamuju. Agar tujuan organisasi dapat dicapai dengan efektif dan efisien, maka Dinas Pertanian Kabupaten Mamuju berusaha meningkatkan kinerja pegawainya, akan tetapi pada kenyataanya masih terdapat pegawai yang kinerjanya masih rendah. Penilaian kinerja pegawai di Dinas Pertanian Kabupaten Mamuju berdasarkan angka sesuai dengan ketentuan yang ada dalam PP No. 10 tahun 1979 tentang penilaian pelaksanaan pekerjaan.

Dalam wawancara awal dengan kepala sub bagian program dan kepegawaian diperoleh informasi bahwa masih banyak pegawai yang kinerjanya masih rendah dan belum optimal untuk memenuhi standar kinerjanya.

Maka dapat diindikasikan bahwa pegawai Dinas Pertanian Kabupaten Mamuju masih banyak yang belum memanfaatkan jam kerjanya untuk menyelesaikan pekerjaan. Dengan demikian, fenomena di atas mengisyaratkan bahwa kinerja pegawai masih tergolong rendah.

Penurunan kinerja pegawai Dinas Pertanian Kabupaten Mamuju memerlukan pemecahan karena berhubungan dengan pelayanan publik khusunya para kelompok tani/gapoktan dan merugikan instansi sendiri dalam pencapaian visi "Mewujudkan Produksi Pertanian Tanaman Pangan Dan Hortikultura Yang Unggul” serta sangat mungkin mengakibatkan menurunnya kinerja organisasi secara totalitas karena baik buruknya kinerja perusahaan atau organisasi merupakan cerminan dari kinerja pegawainya.

Penurunan kinerja pegawai Dinas Pertanian Kabupaten Mamuju dapat dikaji dengan melihat faktor yang mempengaruhi kinerja pegawai. Hal ini sesuai dengan pendapat Siagian (2003, p.2) yang menyatakan "Hubungan antara Kepemimpinan dan Kinerja Keberhasilan suatu organisasi 
baik sebagai keseluruhan maupun berbagai kelompok dalam suatu organisasi tertentu, sangat tergantung pada mutu kepemimpinan yang terdapat dalam organisasi yang bersangkutan.

Selain itu, faktor lain yang mempengaruhi kinerja adalah budaya organisasi. Diyakini oleh para pakar teori organisasi, perilaku organisasi maupun pakar manajemen bahwa, salah satu faktor lingkungan internal organisasi yang mampu memberikan dukungan untuk memacu efektivitas organisasi adalah budaya organisasi (Robbins \& Stephen, 2003). Budaya organisasi didefinisikan sebagai suatu kerangka kerja kognitif yang memuat sikap-sikap, nilai-nilai, norma-norma dan pengharapan-pengharapan bersama yang dimiliki oleh anggota-anggota organisasi (Greenberg, Baron, \& A, 2000)

Budaya organisasi yang ada di lingkungan Dinas Pertanian Kabupaten Mamuju terbentuk melalui perkembangan dan pengalaman organisasi dalam aktivitas penyelenggaraan pemerintahan. Hal tersebut terjewantahkan dalam visi dan misi Dinas Pertanian Kabupaten Mamuju. Visi Dinas Pertanian Kabupaten Mamuju adalah mewujudkan produksi pertanian tanaman pangan dan hortikultura yang unggul.

\section{MASALAH PENELITIAN}

Berdasarkan uraian latar belakang tersebut, dapat dirumuskan beberapa permasalahan penelitian ini sebagai berikut :

1. Apakah faktor budaya organisasi dan komitmen organisasi berpengaruh terhadap kinerja pegawai Dinas Pertanian Kabupaten Mamuju?

2. Variabel mana yang paling dominan berpengaruh terhadap kinerja pegawai Dinas Pertanian Kabupaten Mamuju?

\section{Budaya Organisasi}

Pada hakikatnya budaya organisasi merupakan budaya menjadi acuan di dalam suatu organisasi di mana terdapat sekelompok orang yang melakukan interaksi. Robertr P. Vecchio dalam (Wibowo, 2010) mendefinisikan budaya organisasi sebagai nilai-nilai dan norma-norma bersama yang terdapat dalam suatu organisasi dan mengajarkanya kepada para pekerja yang datang. Budaya organisasi merupakan terjemahan dari organization culture yang dapat definisikan dalam berbagai pengertian. Kreitner dan Kinichi dalam (Suwatno, 2007, p. 79) menyatakan budaya organisasi adalah satu wujud anggapan yang dimiliki, diterima secara implisit oleh kelompok dan menentukan bagaimana kelompok tersebut rasakan, pikirkan dan bereaksi terhadap lingkungannya yang beraneka ragam. 


\section{Jurnal Bisnis, Manajemen dan Informatika}

Menurut Kotter dan Heskett (Benyamin, 1997, p.4), budaya organisasi mempunyai dua tingkatan yang berbeda dilihat dari sisi kejelasan dan ketahanan mereka terhadap perubahan. Tingkatan pertama yaitu pada tingkatan yang lebih dalam dan kurang terlihat, budaya merujuk pada nilai-nilai yang dianut bersama oleh orang dalam kelompok dan cenderung bertahan sepanjang waktu. Bahkan, meskipun anggota kelompok sudah berubah. Pada tingkatan ini, budaya bisa sangat sukar berubah, sebagian karena anggota kelompok sering tidak sadar akan banyaknya nilai yang mengikat mereka bersama, yaitu pada tingkatan yang lebih terlihat, budaya yang menggambarkan pola atau gaya perilaku suatu organisasi sehingga pegawaipegawai baru otomatis terdorong untuk mengikuti perilaku sejawatnya. Budaya dalam pengertian ini, masih kaku untuk berubah, tetapi tidak sesulit pada tingkatan nilai-nilai dasar.

\section{Komitmen}

Komitmen organisasi merupakan sikap yang harus dimiliki oleh setiap pegawai. Komitmen merupakan pengikat yang memberikan dorongan untuk memberikan apa yang terbaik terahadap apa yang menjadi tanggung jawabnya. Becker (yang dikutip oleh Panggabean, 2004, p.135) menggambarkan komitmen organisasi sebagai kecenderungan untuk terikat dalam garis kegiatan yang konsisten karena menganggap adanya biaya pelaksanaan kegiatan lain (berhenti bekerja).

Menurut Allen dan Meyer (1990) sebagai mana dikutip oleh Panggabean (2004, p.135), mendefinisikan komitmen organisasi sebagai sebuah konsep yang memiliki tiga dimensi, yaitu affective, normative dan continuence commitment.

Wagner et.al., (2005, p.143) menjelaskan "Organizational commitment is the degree to which people identify with the organization that employs them." (Komitmen organisasi adalah derajat pengenalan diri setiap individu dengan organisasi yang mempekerjakannya).

\section{Kinerja}

Kinerja merupakan performance atau unjuk kerja. Kinerja dapat pula diartikan sebagai prestasi kerja atau pelaksanaan kerja atau hasil unjuk kerja. Maier menyatakan penilaian kinerja atau prestasi kerja sebagai suatu kesuksesan yang dihasilkan seseorang dalam melaksanakan suatu pekerjaan. Lebih tegas lagi Lawler and Poter dalam (As'ad, 2003, p.46). menyatakan bahwa kinerja adalahsuccesfull role achievement yang diperoleh seseorang dari perbuatannya Berdasarkan hal tersebut, maka kinerja atau prestasi kerja merupakan hasil yang dicapai seseorang menurut ukuran yang berlaku, dalam kurun waktu tertentu, berkenaan dengan pekerjaan serta perilaku dan tindakannya. 
Menurut Cascio (1998, p.275) "Performance refer to an employees accomplishment of assing task. Kinerja adalah penyelesaian tugas yang diberikan kepada para Pegawai. Prestasi kerja adalah hasil yang dicapai oleh Pegawai dalam bekerja. Menurut Mangkunegara (2001, p. 67), kinerja adalah hasil kerja secara kualitas dan kuantitas yang dicapai oleh seorang pegawai dalam melaksanakan tugasnya sesuai dengan tanggung jawab yang diberikan kepadanya.

Cash dan Fischer (1987) mengemukakan bahwa kinerja sering disebut dengan performance atau result yang diartikan dengan apa yang telah dihasilkan oleh individu pegawai. Kinerja dipengaruhi oleh kinerja organisasi (organizational performance) itu sendiri yang meliputi pengembangan organisasi (organizational development), rencana kompensasi (compensation plan), sistem komunikasi (communication system), gaya manajerial (managerial style), struktur organisasi (organization structure), kebijakan dan prosedur (policies and procedures)

Veithzal dan Ella Jauvani (2009, p.548) menyatakan bahwa kinerja merupakan fungsi dari motivasi dan kemampuan. Untuk menyelesaikan tugas atau pekerjaan seseorang sepatutnya memiliki derajat kesediaan dan tingkat kemampuan tertentu. Kinerja merupakan perilaku nyata yang ditampilkan setiap orang sebagai prestasi kerja yang dihasilkan oleh pegawai sesuai dengan perannya dalam perusahaan. Kinerja pegawai merupakan suatu hal yang sangat penting dalam upaya perusahaan untuk mencapai tujuannya.

\section{HIPOTESIS}

1. Budaya organisasi dan komitmen organisasi berpengaruh terhadap kinerja pegawai Dinas Pertanian Kabupaten Mamuju.

2. Variabel komitmen berpengaruh dominan terhadap kinerja pegawai Dinas Pertanian Kabupaten Mamuju.

\section{METODE}

\section{a. Desain Penelitian}

Penelitian ini adalah menggunakan metode kuantitatif dengan pendekatan eksplanatori, yakni suatu metode penelitian menggunakan perspektif pendekatan kuantitatif dengan tipe eksplanatori yang akan digunakan untuk menjelaskan apakah ada pengaruh antara budaya organisasi, dan komitmen organisasi terhadap kinerja pegawai

\section{b. Populasi dan Sampel}

Dalam penelitian ini yang menjadi populasi adalah seluruh pegawai Dinas Pertanian Kabupaten Mamuju yang berjumlah 35 pegawai

\section{c. Defenisi Operasional}




\section{Jurnal Bisnis, Manajemen dan Informatika}

Budaya Organisasi merupakan sesuatu yang dipegang secara intensif, secara luas dianut dan semakin jelas disosialisasikan dan diwariskan dan berpengaruh terhadap lingkungan dan perilaku manusia”. Budaya yang kuat akan mendukung terciptanya sebuah prestasi yang positif bagi anggotanya dalam hal ini budaya yang diinternalisasikan pihak pimpinan akan berpengaruh terhadap sistem perilaku para pendidik dan staf di bawahnya baik di dalam organisasi maupun di luar organisasi

Komitmen Organisasi merupakan sesuatu hal yang lebih dari kesetiaan yang pasif terhadap organisasi, atau menyiratkan hubungan pegawai dengan perusahaan atau organisasi secara aktif.

Kinerja merupakan hasil-hasil fungsi pekerjaan seseorang atau kelompok dalam suatu organisasi pada periode waktu tertentu yang merefleksikan seberapa baik seseorang atau kelompok tersebut memenuhi persyaratan sebuah pekerjaan dalam usaha pencapaian tujuan organisasi.

\section{d. Instrumen Penelitian}

Penelitian ini menggunakan kuesioner atau daftar pertanyaan, yakni pengumpulan data dengan bantuan daftar pertanyaan yang disusun secara tertulis, sistematis, dan sudah disediakan pilihan jawabannya dalam bentuk pertanyaan tertutup yang sudah disiapkan dulu kemudian disajikan pada responden. Angket ini menggunakan pertanyaan skala likert.

\section{e. Alat Analisis}

Analisis data yang digunakan dalam penelitian ini untuk melihat keterkaitan antara budaya organisasi, dan komitmen organisasi terhadap kinerja pegawai Dinas Pertanian Kabupaten Mamuju, seperti yang terlihat pada hipotesis, maka dalam penelitian ini digunakan regresi linear berganda dengan formulasi sebagai berikut :

$$
Y=b_{0}+b_{1} X_{1}+b_{2} X_{2}+e i
$$

$$
\begin{aligned}
& \text { Di mana : } \mathrm{Y}=\text { Kinerja pegawai } \\
& \mathrm{X}_{1} \quad=\text { Budaya Organisasi } \\
& \mathrm{X}_{2} \quad=\text { Komitmen Organisasi } \\
& \mathrm{b}_{0} \quad=\text { Konstanta } \\
& b_{1}, b_{2}, b_{3}=\text { Koefisien regresi (parameter) yang diestimasi } \\
& \mathrm{e}_{\mathrm{i}} \quad=\text { Faktor kesalahan (error) }
\end{aligned}
$$

\section{HASIL PENELITIAN}




\section{Analisis Kuantitatif}

Pengujian terhadap hasil regresi yang diperoleh dilakukan pengujian secara serempak dengan menggunakan uji-F dan pengujian secara parsial dengan menggunakan uji-t. Maka dapat diuraikan untuk lebih jelasnya :

\section{Pengujian Hipotesis Secara Parsial}

Pengujian Hipotesis secara parsial ini digunakan untuk melihat pengaruh dari variabel Budaya organisasi dan komitmen organisasi terhadap kinerja pegawai pada Dinas Pertanian Kabupaten Mamuju. Hasil pengujiannya dapat dilihat dari nilai t-hitungnya.

Tabel 1. Pengujian Secara Parsial (Uji-t)

\begin{tabular}{|c|c|c|c|}
\hline Variabel Independent & $\begin{array}{c}\text { Koefisien } \\
\text { Regresi (B) }\end{array}$ & Sig \\
\hline Budaya Oganisasi (X1) & 0,389 & 2.787 & 0,009 \\
Komitmen organisasi (X2) & 0,411 & 2.869 & 0,007 \\
\hline Konstanta $\left(\mathrm{b}_{0}\right)$ & & 0,741 & \\
\hline
\end{tabular}

Sumber : Output SPSS yang Diolah, 2017

Berdasarkan pengujian secara parsial seperti pada tabel 1 menunjukkan bahwa budaya organisasi dan komitmen secara individu berpengaruh signifikan dan positif terhadap kinerja pegawai pada Dinas Pertanian Kabupaten Mamuju. Hal ini dapat diketahui dari nilai t-hitung yang diperoleh lebih besar dari t-tabel atau t-hitung lebih kecil dari t-tabel.

Selanjutnya pada tabel 1 , dapat diketahui bahwa hasil persamaan regresi linier berganda dari model penelitian ini adalah sebagai berikut :

$$
\mathrm{Y}=0,741+0,389 \mathrm{X}_{1}+0,411 \mathrm{X}_{2}
$$

Berdasarkan persamaan regresi linier berganda tersebut di atas, maka dapat diinterpresentasikan sebagai berikut ini :

a. Konstanta $\left(b_{0}\right)$ diperoleh dari nilai 0,741 yang menyatakan bahwa besarnya kinerja pegawai pada Dinas Pertanian Kabupaten Mamuju Majene terdiri dari budaya organisasi dan komitmen organisasi.

b. $b_{1}=0,389$, mempunyai arti positif yang menunjukkan bahwa budaya organisasi berpengaruh positif terhadap kinerja pegawai pada Dinas Pertanian Kabupaten Mamuju, koefisien $b_{1}$ tersebut signifikan dikarenakan nilai $p=0,009$ lebih kecil dari 0,05. Dapat dijelaskan bahwa apabila ada peningkatan dan variabel lainnya konstan, maka akan meningkatkan kinerja pegawai pada Dinas Pertanian Kabupaten Mamuju. 


\section{Jurnal Bisnis, Manajemen dan Informatika}

c. $b_{2}=0,411$, memiliki tanda positif yang menunjukkan bahwa komitmen organisasi berpengaruh positif dan signifikan terhadap kinerja pegawai pada Dinas Pertanian Kabupaten Mamuju. Koefisien $b_{2}$ tersebut signifikan karena nilai $p=0,007$, lebih kecil dari 0,05. Hal tersebut dapat dijelaskan apabila terjadi peningkatan komitmen organisasi dan variabel bebas lainnya konstan, maka akan terjadi peningkatan kinerja pegawai pada Dinas Pertanian Kabupaten Mamuju.

Besarnya kontribusi yang diberikan dari variabel budaya organisasi dan komitmen organisasi terhadap kinerja pegawai pada Dinas Pertanian Kabupaten Mamuju dan dapat dilihat dari koefisien determinasinya. Perolehan nilai determinasi $\left(\mathrm{R}^{2}\right)$ dapat dilihat pada tabel dibawah ini :

Tabel 2. Hasil pengujian Koefisien Determinasi $\left(\mathrm{R}^{2}\right)$

\begin{tabular}{|c|c|c|c|}
\hline \multirow{2}{*}{ Model } & $\mathrm{R}$ & R Square & Adjusted R Square \\
\hline 1 & $0,764^{@}$ & 0,583 & 0,557 \\
\hline
\end{tabular}

Sumber : Output SPSS yang diolah, 2017

Berdasarkan hasil uji determinasi tabel tersebut diatas, maka dapat dijelaskan bahwa besarnya koefisien determinasi $\left(\mathrm{R}^{2}\right)$ adalah 0,583. Angka koefisien determinasi menyatakan bahwa variabel budaya organisasi, dan komitmen organisasi memberikan kontribusi atas variasi perubahan kinerja Pegawai sebesar 58,3\%. Sedangkan sisanya sebesar 41,7\% dipengaruhi oleh variabel-variabel lain yang tidak dilibatkan dalam penelitian ini.

\section{PEMBAHASAN}

\section{Pengaruh Budaya Organisasi Terhadap Kinerja Pegawai}

Hasil pengujian hipotesis telah membuktikan terdapat pengaruh antara budaya organisasi terhadap kinerja Pegawai pada Kantor Dinas Pertanian Kabupaten Mamuju. Melalui hasil perhitungan yang telah dilakukan diperoleh nilai mempunyai $t_{\text {hitung }}$ sebesar 2.787 dengan tingkat signifikansi sebesar 0,009 yang lebih kecil dari $\quad \alpha(0,009<0,050)$. ini berarti bahwa budaya organisasi secara parsial berpengaruh positif dan signifikan terhadap kinerja Pegawai pada Kantor Dinas Pertanian Kabupaten Mamuju.

Penelitian ini juga didukung oleh penelitian terdahulu yang dilakukan oleh Rafidah Nur (2007), hasil penelitian tersebut menunjukkan bahwa terdapat pengaruh budaya organisasi yang 
terdiri dari inisiatif, individu, toleransi, resiko. dan dukungan manajemen terhadap peningkatan prestasi kerja pegawai pada Dinas Pengelolaan Sumber Daya Air Provinsi Sulawesi Selatan.

Budaya organisasi sebagai suatu sistem makna bersama yang dianut oleh anggota-anggota yang membedakan organisasi itu dengan organisasi-organisasi lain (Robbins, 1996, p.721).Budaya organisasi secara keseluruhan merupakan organisasi dalam dirinya sendiri, karena budaya melekat pada organisasi

\section{Pengaruh Komitmen Organisasi $\left(X_{3}\right)$ Terhadap Kinerja Pegawai di Kabupaten Mamuju}

Hasil pengujian hipotesis telah membuktikan terdapat pengaruh antara komitmen terhadap kinerja Pegawai pada Kantor Dinas Pertanian Kabupaten Mamuju. Melalui hasil perhitungan yang telah dilakukan diperoleh nilai mempunyai $\mathrm{t}$ hitung sebesar 2.869 dengan tingkat signifikansi sebesar 0,007 yang lebih kecil dari $\alpha(0,007<0,050)$. ini berarti bahwa komitmen secara parsial berpengaruh positif dan signifikan terhadap kinerja Pegawai pada Kantor Dinas Pertanian Kabupaten Mamuju. Artinya bahwa ada pengaruh positif dan signifikan antara variabel motivasi terhadap terhadap kinerja Pegawai pada Kantor Dinas Pertanian Kabupaten Mamuju.

Hasil analisis ini mendukung penelitian yang dilakukan oleh oleh Nurjannah (2015), di mana hasil penelitian menunjukkan bahwa variabel komitmen organisasi merupakan variabel yang dominan pengaruhnya terhadap kinerja karyawan pada Biro Lingkup Departemen Pertanian Kabupaten Mamuju.

\section{KESIMPULAN DAN SARAN}

a. Hasil penelitian menunjukkan bahwa variabel, budaya organisasi dan komitmen organisasi secara bersama-sama berpengaruh secara positif dan signifikan terhadap kinerja pegawai Dinas Pertanian Kabupaten Mamuju.

b. Hasil analisis menunjukkan bahwa dari kedua variabel independen yang diteliti, variabel komitmen organisasi mempunyai pengaruh paling dominan terhadap kinerja pegawai Dinas Pertanian Kabupaten Mamuju.

\section{KETERBATASAN PENELITIAN}

Penelitian ini masih menggunakan sampel yang terbatas dan masih dalam lingkup yang lebih kecil, sehingga belum sepenuhnya dapat memberikan gambaran yang akurat. Perlu dilakukan penelitian lebih lanjut mengenai kinerja pegawai Dinas Pertanian Kabupaten Mamuju. Hal ini didasari oleh hasil analisis yang menunjukkan budaya organisasi dan komitmen organisasi hanya mampu memberikan kontribusi 58,3\% dalam menjelaskan kinerja pegawai, jadi 


\section{Jurnal Bisnis, Manajemen dan Informatika}

disarankan untuk memasukkan variabel-variabel lain yang belum diteliti yang dapat mempengaruhi kinerja seperti motivasi, kepuasan kerja, kecerdasan spiritual dan lain sebagainya.

\section{DAFTAR PUSTAKA}

As'ad, Moh. 2003. Produktifitas Kerja Karyawan. ED 4 .Yogyakarta: Liberty.

Cascio, Wayne F. 1998. Managing Human Resources: Productivity, Quality of Work Life,

Profits. Mc-Graw Hill International Edition: New York.

Cash, W.H. and F.E. Fischer. 1987. Human Resource Planning. Dalam Famularo, J.J., Hand Book of Human Resources Administration (hlm 10.3-10.20). Singapore: Fong and Sons Printers Pte Ltd

Dessler, Gary. 1997. Manajemen Sumber Daya Manusia. Prenhallindo: Jakarta.

Djarwanto.P. 1998. Metode Penelitian untuk Skripsi dan Tesis Bisnis. Raja Grafindo Persada., Jakarta.

Greenberg, Baron, \& A, R. 2000. Organizational Behaviuor. Griffin: Prentice Hall.

Kotter, John P. dan James L. Heskett. 1997. Corporate Culture and Performance. Alih Bahasa Benyamin Molan.PT Prenhalindo: Jakarta.

Mangkunegara, Anwar Prabu. 2001. Manajemen Sumber Daya Manusia Perusahaan. PT Remaja Rosdakarya: Bandung

Mathis, R.L, dan J.H, Jackson. 2000. Manajemen Sumber Daya Manusia. Salemba Empat: Jakarta.

Nurjannah. 2008. Pengaruh Gaya Kepemimpinan dan Budaya Organisasi Terhadap Komitmen Organisasi Dalam Meningkatkan Kinerja Pegawai (Studi Pada Biro Lingkup Departemen Pertanian). Tesis Program Pascasarjana Universitas Diponegoro: Semarang.

Panggabean, Mutiara, S. 2004. Manajemen Sumber Daya Manusia. $\quad$ GI : Bogor. Rafidah Nur. 2007. Pengaruh Budaya Organisasi dan Komitmen Organisasi Terhadap Prestasi Kerja Pada Dinas Pengelolaan Sumber Daya Air Provinsi Sulawesi Selatan. Tesis Program Pascasarjana Universitas Muslim Indonesia: Makassar.

Robbins, Stephen. 2003. Organizational Behaviour. Tenth Edition. New Jersey : Pearson Education, Inc.

Sedarmayanti. 2007. Manajemen Sumber Daya Manusia, Reformasi Birokrasi \& Manajemen Pegawai Negeri Sipil. Refika Aditama: Bandung. 
Siagian, P. Sondang. 2003. Kerangka Dasar Ilmu Administrasi. PT Rineka Cipta: Jakarta. Simamora, Henry. 2004. Manajemen Sumber Daya Manusia. STIE YKPN: Yogyakarta.

Singarimbun, Masri dan Sofyan Effendy. 1998. Metode Penelitian Survai. PT Pustaka LP3ES. Jakarta.

Tangkilisan, Hesel Nogi. 2002. Manajemen SDM Birokrasi Publik : Strategi Keunggulan Pelayanan Publik. YPAPI :Yogyakarta.

Veithzal Rivai dan Ella Jauvani S. 2009. Manajemen Sumberdaya Manusia untuk Perusahaan: Dari Teori ke Praktik. PT Rajagrafindo Persada: Jakarta.

Wagner and Hollenbeck. 2005. Organizational Behaviour, Securing Competitive Advantage. Thomson: South Western. 